(C) 2021 IEEE

26th International Conference on Electricity Distribution - CIRED

\title{
Improving Energy Efficiency in DC Microgrids with Integrated Energy Storage
}

S. Kim, J. Kucka, S. Kim, et al.

This material is posted here with permission of the IEEE. Such permission of the IEEE does not in any way imply IEEE endorsement of any of EPFL's products or services. Internal or personal use of this material is permitted. However, permission to reprint / republish this material for advertising or promotional purposes or for creating new collective works for resale or redistribution must be obtained from the IEEE by writing to pubs-permissions@ieee. org. By choosing to view this document, you agree to all provisions of the copyright laws protecting it. 


\title{
Improving Energy Efficiency in DC Microgrids with Integrated Energy Storage \\ Seongil Kim ${ }^{1,2 *}$,Jakub Kucka ${ }^{2}$, Soo-Nam Kim ${ }^{1}$, and Drazen Dujic ${ }^{2}$
}

\author{
${ }^{1}$ Future Power Grid Research Department, Hyundai Electric \& Energy Systems, Yongin 16891, Republic of Korea \\ ${ }^{2}$ Power Electronics Laboratory, École Polytechnique Fédérale de Lausanne (EPFL), 1015 Lausanne, Switzerland \\ *kim.seongil@hyundai-electric.com
}

Keywords: DC Microgrids, Energy Management, Energy Storage, Marine DC Networks, Solid-State Technology

\begin{abstract}
This paper experimentally demonstrates highly efficient and emission-free operating modes of marine DC microgrids by integrating energy storage systems. Laboratory-scaled DC microgrids including a central controller are established to mimic marine low-voltage DC microgrids, commercially built. Two supercapacitor banks are employed in the DC microgrids as integrated energy storage. With the microgrids, three operating modes which are available in DC vessels with integrated energy storage are experimentally demonstrated: load leveling - keeping generator loads within generator's optimal operating ranges and minimising a number of running generators by charging energy for light load and discharging it for overload, transient mitigation improving transient system performance and reducing transient engine emissions by fast-response energy storage systems, and zero emission - shutting down onboard generators while in a port with electrical power supply from energy storage systems or onshore power grids. Furthermore, potential benefits of the above ship operating modes are discussed from the experimental test results. This study proves that the integrated energy storage can provide high potential for the energy savings as well as allow for achieving zero-emission ports.
\end{abstract}

\section{Introduction}

A shipping industry is one of the top sectors that produce greenhouse gas emissions. To counteract the impact on the climate change, International Maritime Organization (IMO) adopted energy-efficiency regulations in 2011 - Energy Efficiency Design Index (EEDI) and Ship Energy Efficiency Management Plan (SEEMP) [1]. In accordance with the EEDI as presented in Tab 1, newly constructed ships of 400 gross tonnages and above have to increase the energy efficiency to meet the reduction rates, defined over the three phases. Finally, by 2025 , the ships have to be designed to have $30 \%$ less energy consumption than those built in 2004 .

Table 1 Reduction percentages to comply with EEDI [1].

\begin{tabular}{cccc}
\hline \hline Ship Type & Phase 1 & Phase 2 & Phase 3 \\
& $2015-2019$ & $2020-2024$ & 2025 \\
\hline Bulk carrier & 10 & 20 & 30 \\
Gas carrier & 10 & 20 & 30 \\
Tanker & 10 & 20 & 30 \\
Container ship & 10 & 20 & 30 \\
General cargo ship & 10 & 15 & 30 \\
Refrigerated & 10 & 15 & 30 \\
cargo carrier & 10 & 20 & 30 \\
Combination carrier & 10 \\
\hline \hline
\end{tabular}

On the other hand, there have been active movements to power vessels by zero-emission fuels in a port (a short term goal) and during deep-sea shipping (a long term goal). To achieve the zero emission, burning fossil fuels that are still the main energy sources has to be avoided. In other words, any form of energy loaded on the ship has to be transformed into electrical energy as the electrical energy can be converted into many forms without carbon dioxide emissions.

The energy efficiency regulations and the zero-emission movements are creating incentives for the energy storage integration into the onboard networks. Moreover, technological advancements in power and energy density of ESSs (especially lithium-ion battery systems), followed by the cost reduction, have accelerated the ESS integration into the networks (see Fig. 1). Under this recent trend, this study is conducted to investigate how to utilise ESSs in marine DC microgrids for highly efficient and emission-free ship operation.

For the study, two-bus DC microgrids are implemented, consisted of two power supply sets connected through a solid-state bus-tie switch (BTS), two supercapacitor banks controlled by DC-DC converters (act as ESSs), three resistive loads, and a main controller. In scaled-down marine DC microgrids, three ship operating modes are experimentally demonstrated with indepth discussions on potential benefits: load leveling - reducing large fluctuations in actual generator loads, transient mitigation - improving transient system performances, and zero emission - powering ships without carbon dioxide emissions. 


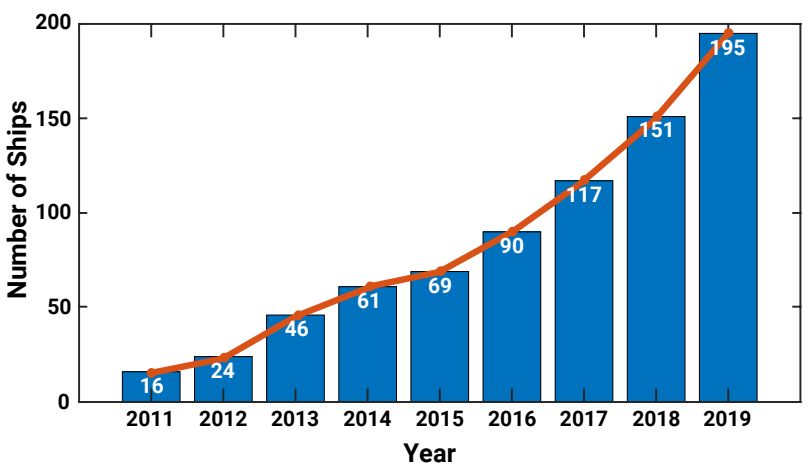

Fig. 1 Ships with installed battery energy storage systems [4]. Up to now battery energy storage systems have been installed in nearly 200 ships.

\section{Two-Bus Marine DC Microgrids}

This section describes hardware components of the implemented DC microgrids, rated $35 \mathrm{kVA}$ and $500 \mathrm{~V}_{\mathrm{DC}}$. The DC microgrids are composed of two DC motor-synchronous generator sets, two rectifiers, a solid-state BTS, busbars, two supercapacitor banks, two DC-DC converters, and three resistive loads, as depicted in Fig. 2 and summarised in Table 2.

\subsection{Motor-Synchronous Generator Sets}

Whereas the microgrids are formed with DC, power generation is still relied on matured and cost effective AC technologies, i.e., the combination of an electrical generator and an engine (a prime mover). To mimic this combination, a DC motor driven by a thyristor power converter is combined with a synchronous generator for each power generation set. The utilised automatic voltage regulator (AVR, ABB Unitrol 1005) is for AC voltage regulation (lack of the DC regulation function), and thus, a

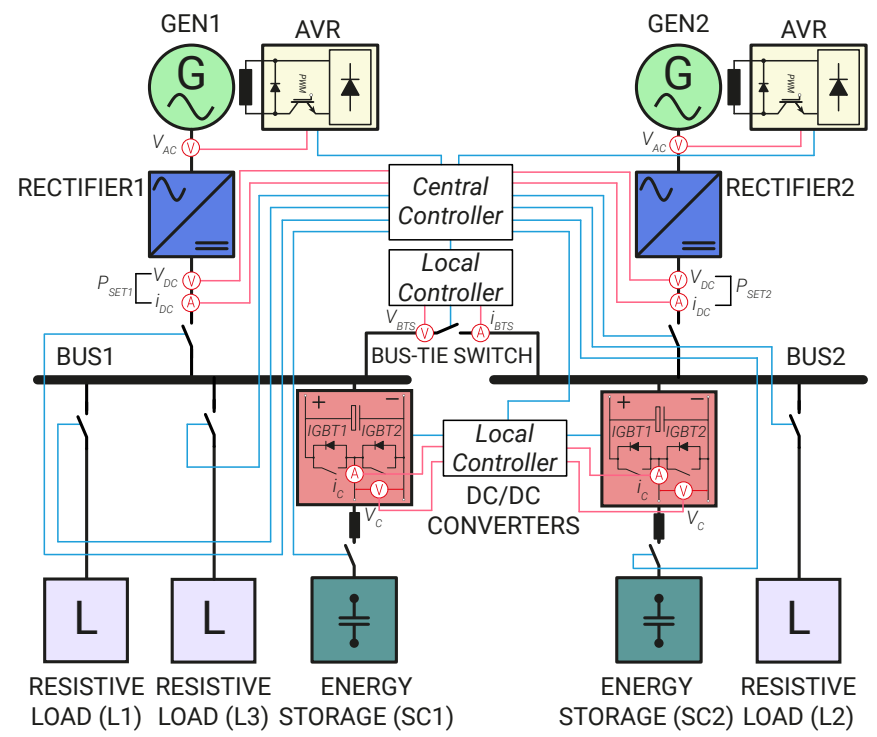

Fig. 2 Schematic diagram of the implemented two-bus DC microgrids.
Table 2 Specification of main components in the implemented DC microgrids.

\begin{tabular}{cc}
\hline \hline Component & Specification \\
\hline GEN1 (AVR) & $10 \mathrm{kVA}, 380 \mathrm{~V}, 50 \mathrm{~Hz}$ (Unitrol 1005) \\
GEN2 (AVR) & $25 \mathrm{kVA}, 380 \mathrm{~V}, 200-400 \mathrm{~Hz}$ (Unitrol 1005) \\
Rectifier & Six-pulse diode rectifier (670 V, 91 A) \\
BTS & Solid-state type (600 V, 100 A) \\
ESS & Two supercapacitor banks (2 x 160 kJ) \\
DC-DC & Two half-bridge modules (800 V, 32 A) \\
Converter & \\
Load & Three resistors $(2 \times 2.5 \mathrm{~kW}$ and $1 \times 3 \mathrm{~kW})$ \\
\hline
\end{tabular}

central controller (implemented with Pixsys TD820) helps the AVR regulate the DC voltage by providing an AC reference in proportion to a DC voltage error.

\subsection{Rectifiers, BTS, and Loads}

A three-phase six-pulse diode rectifier (SEMIKRON SKKD 100/16) including DC-link capacitors at its terminal is employed to each generator set for the rectification. An oversized diode rectifier $(670 \mathrm{~V}$ and $91 \mathrm{~A})$ is installed to conduct various tests.

A solid-state BTS, available in the laboratory, is integrated into the microgrids. The BTS has a topology of a four-quadrant switch configuration with one IGBT module and a current limiting reactor $[5,6]$. With this topology, the BTS allows for bi-directional power flows and ultra-fast current interruption (several tens of microseconds) [5].

Two of $2.5 \mathrm{~kW}$ resistive loads and one of $3 \mathrm{~kW}$ resistive load, available in the laboratory, are connected to the microgrids.

\subsection{ESSs with DC-DC Converters}

Due to lack of access to suitable batteries for the microgrids, alternative technology (supercapacitor bank) is used, without major negative effect on the performances that this paper aims to demonstrate. Two pairs of two supercapacitors are connected in series and then these series-connected supercapacitors are wired in parallel. With this configuration each supercapacitor bank is rated for $160 \mathrm{~kJ}$.

These supercapacitor banks are coupled in the microgrids via DC-DC converters. Two of half-bridge power modules (Imperix PEB 8032, $800 \mathrm{~V}$ and $32 \mathrm{~A}$ ) are used for controlled

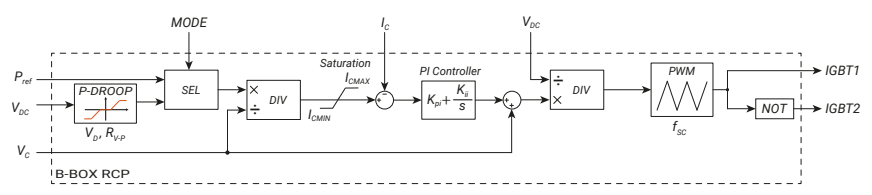

Fig. 3. Block diagram of DC-DC converter control. 


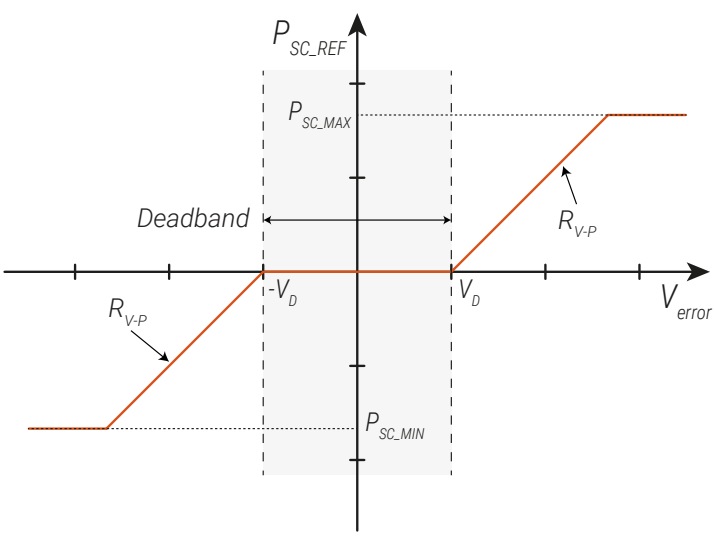

Fig. 4. Implemented power droop control.

charging and discharging of the supercapacitor banks. As presented in Fig. 3, the supercapacitor banks can be charged by modulating the upper IGBT (IGBT1 in Fig. 2), acting as a buck converter. On the other hand, the DC-DC converters can boost the DC-link voltage with the PWM switching of the lower IGBT (IGBT2 in Fig. 2). The power input of the converters can directly be set or can be calculated by the DC power droop characteristics implemented in the DC-DC converter controller (Imperix B-Box RCP), as shown in Fig. 4. In this study, the direct power reference is fed to the converter controller for the load leveling. On the other hand, the transient migitation and zero-emission modes rely on the power droop control.

\section{Load Leveling}

The power demand of ships is highly dependent on ship operating modes [7]. In case of long-distance cruising (a normal seagoing mode), it consumes the minimum electrical power and its profile may be stable. On the other hand, the dynamic positioning mode in harsh weather conditions requires the maximum number of running generators, and also the power demand in this condition is heavily fluctuated depending on wind, sea-wave, and so forth. The effectiveness of the ESS integration can be maximised for such dynamic positioning ships, e.g., shuttle tankers, drillships, and platform support vessels.

The demonstration of the load leveling proves that the generator load can be maintained within load leveling ranges (the optimal operating ranges of the ship engine-generator set, typically $60-100 \%$ loads [8]) for highly variable loads. The control scheme of the load leveling is presented in Fig. 5. When the

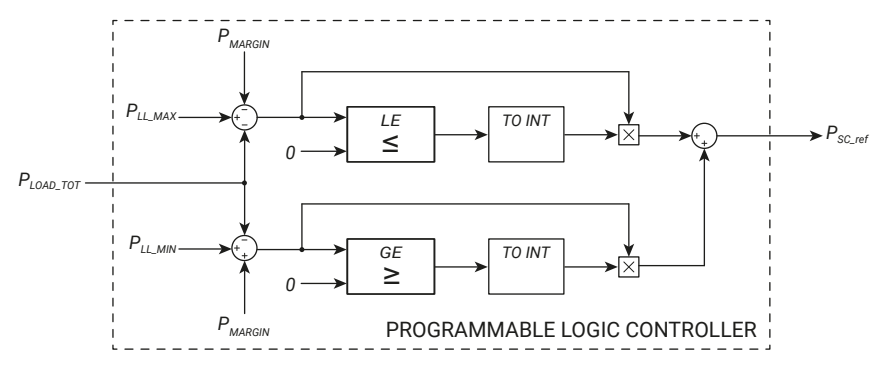

Fig. 5. Block diagram of load leveling control.

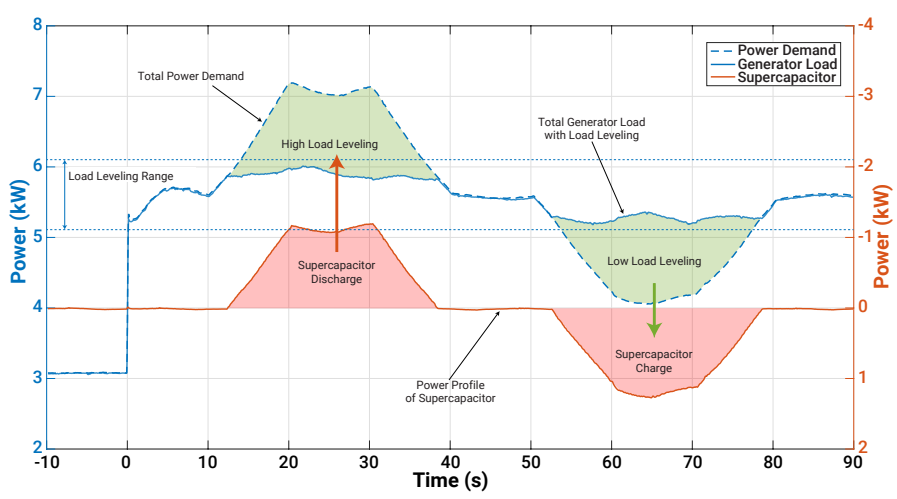

Fig. 6. Demonstration of load leveling operating mode.

power demand reaches the upper or lower power threshold, the ESS discharges its stored energy to the networks or charges the energy into the ESS under this control scheme. This allows for operating the control ranges from $5.1 \mathrm{~kW}$ to $6.1 \mathrm{~kW}$ selected in the study (see Fig. 6).

On the other hand, it is also possible to reduce the number of running generator sets as the ESS provides spinning reserve for the marine microgrids. In the demonstrated case in Fig. 6, if the maximum rating of the running generator set is $6.5 \mathrm{~kW}$, two generator sets have to be operated to fulfill the power demand of around $7.1 \mathrm{~kW}$ in the study. Since the integrated ESS can provide the electrical power of $3.0 \mathrm{~kW}$, it enables to run only one generator set operated in its optimal range and the rest of the power demand can be supplied by the ESS. To conclude, the optimisation of the actual loads and the running generator numbers associated with the load leveling can provide huge potential to improve the ship energy efficiency.

\section{Transient Mitigation}

There are several DC solutions to transit the marine network form from AC to DC. Among them, two dominant DC solutions utilise a synchronous generator combined with a diode rectifier (BlueDrive PlusC [9]) and a thyristor rectifier (Onboard DC Grid [10]). Dynamic performance of these solutions are governed by an exciter and/or a thyristor control, and therefore, their dynamic responses are much slower than the DC solutions based on voltage source converters. Once ESSs are integrated into marine DC microgrids through converters, the transient performance of these solutions can be improved with the fast control action of converters. It enables to avoid transient generator loads by rapidly discharging or charging energy during the transient period. This allows for increasing lifespan of a ship engine-generator set and reducing air pollutants generated during high transients. Furthermore, the regenerative energy from a decelerated induction machine, which is dissipated by braking resistors to prevent a system overvoltage, can be stored in ESSs.

The demonstration of the transient mitigation shows that the transient performance of the diode rectified-based DC microgrids used in the study can be improved by the ESSs with their short time constants, as shown in Fig. 7. Two voltage 


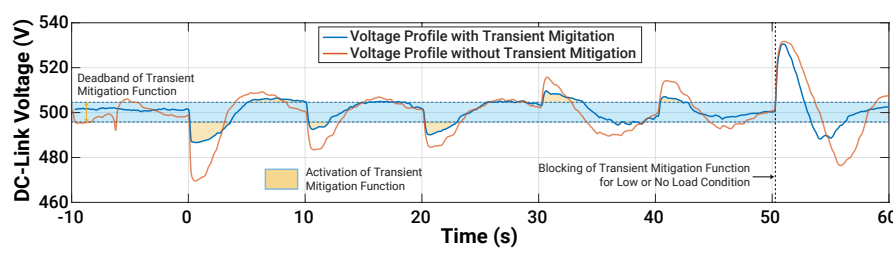

$a$

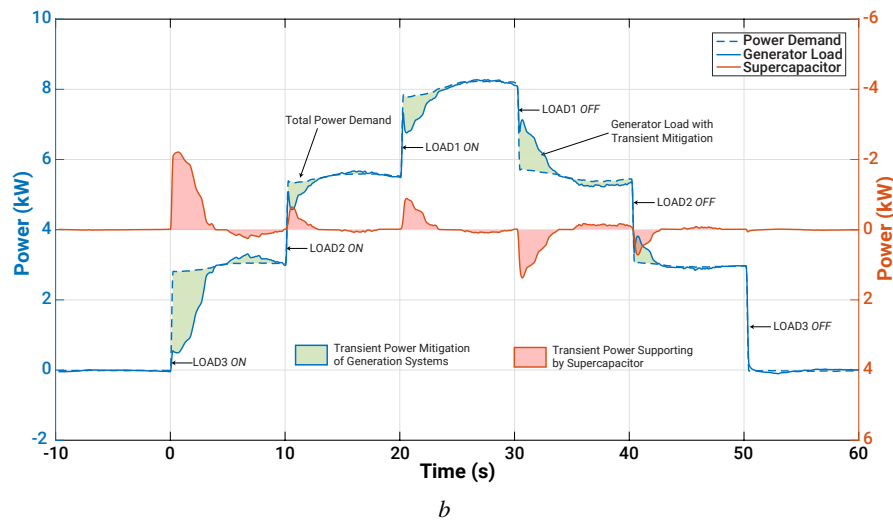

Fig. 7 Demonstration of transient mitigation operating mode: (a) voltage profile and (b) power profile.

and power profiles with and without the transient mitigation control are compared to clearly present the study result. When the voltage is out of the deadband of the transient mitigation control, the ESS discharges or charges the energy with regards to the droop characteristics (see Fig. 4). These ESS actions can mitigate the voltage variance [see Fig. 7(a)] and make the actual generator load softer [see Fig. 7(b)]. Moreover, if the system voltage becomes higher than the upper level of the deadband, the ESS can reduce the voltage increase by reserving the excessive energy. Consequently, the transient mitigation mode demonstrated with the power droop control of the ESS can give the three main benefits: the faster system response, the cleaner system operation, and the higher efficiency (the energy harvesting).

\section{$5 \quad$ Zero Emission}

A port can be free from pollution with ESSs equipped in ships. For instance, whereas ships cannot go long-distance cruising only with ESSs due to low energy density of currently viable technologies, they can switch their power source from diesel generators to ESSs when they are approaching a port for a short period of time, called the zero-emission mode. In a port, shore-to-ship power connection (also called AMP Alternative Maritime Power) is possible [11]. This means that onshore grids not only supply power to all onboard loads, but also recharge the onboard storage. The zero-emission mode, solely powered by ESSs, can be activated with fully charged ESSs when ships are leaving a port. Regarding that, there are wide range of activities to meet environmental regulations and to make a cleaner port $[2,3]$. To achieve this goal, the zero-emission operation is crucial.

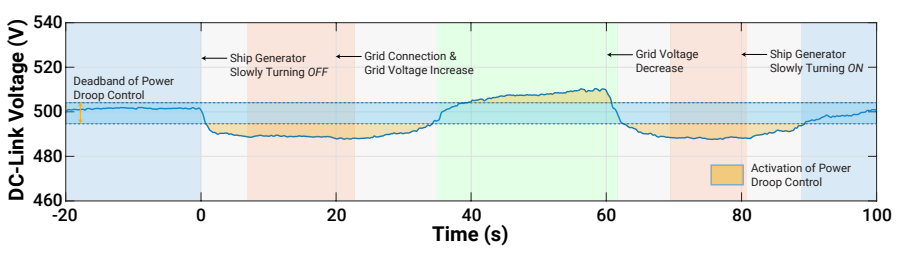

$a$

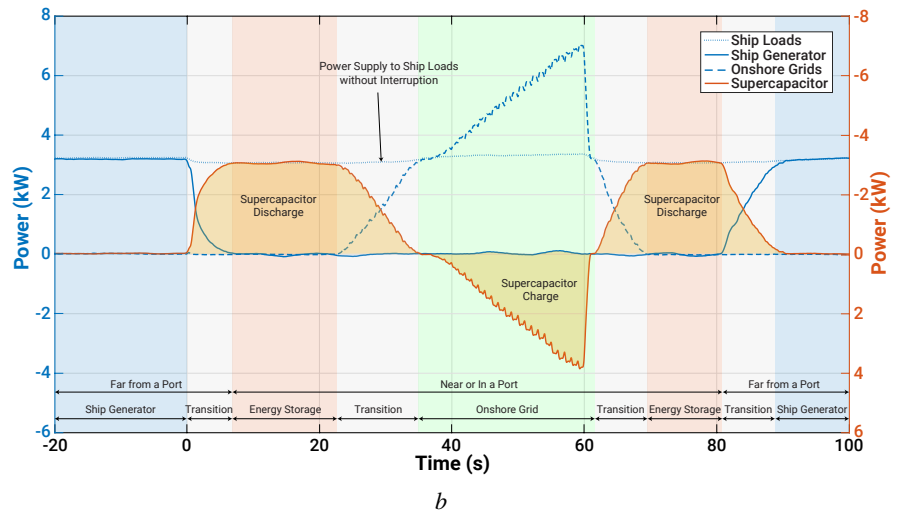

Fig. 8 Demonstration of zero-emission operating mode: (a) DC-link voltage and (b) power profile. Several power source transitions are conducted without power interruption.

For the zero-emission operation, several electrical source transitions are necessary from onboard generators to ESSs, from ESSs to onshore grids, from onshore grids to ESSs, and from ESSs to onboard generators. These transitions are fully demonstrated in the laboratory-scaled microgrids with the power droop control. The full process of the ship entering and departing is assumed. When a ship approaches a port, the onboard generators are slowly turned off at $0 \mathrm{~s}$ in Fig. 8. This causes the voltage drop of the system, followed by the power supply from the ESSs. After the transition, the ESSs become the only power source in the system. The shore-to-ship power supply provides the electricity to the ship while in a port at 20 s. After the connection of the ship networks and the grids, the grids can power the ship networks and the increased grid voltage allows for charging the ESSs with regards to their power droop characteristics. Once the ESSs are fully charged, the ship can depart the port with the ESS-powered operation at around $70 \mathrm{~s}$.

The experimental test demonstrates that continuous power supply to onboard loads without air pollutant emission in a port can be realised with the power droop control of ESSs.

\section{Conclusion}

This paper has presented improved DC microgrid operations with integrated energy storage by demonstrating the three operating modes: load leveling, transient mitigation, and zero emission.

The study results clearly show the advantages of the integrated energy storage in marine DC microgrids. First, it can 
provide great potential to save fuels by the load leveling. Secondly, the DC microgrids can be faster, cleaner, and more efficient with the transient mitigation. Finally, the zero-emission operation can be realised easily with the simple power droop control.

We emphasise again that, by employing energy storage systems into the marine networks, ship owners not only take a big incentive in ship operational costs, but also contribute to reducing global warming from the marine sector.

\section{References}

[1] IMO Resolution MEPC.203(62): 'International Convention for the Prevention of Pollution from Ships (MARPOL)', 2011

[2] 'Oslo's Ambitious Plan to Decarbonize Its Port', https://www.bloomberg.com/news/articles/201911-08/oslo-s-ambitious-plan-to-decarbonize-its-port, accessed 17 February 2021

[3] 'Zero-Emission Alliance Set 2030 Goal', https://www.greenport.com/news101/Projects-andInitiatives/2030-goal-set-for-zero-emission-shipping, accessed 17 February 2021

[4] Kim, S., Ulissi, G., Kim, S.-N., and Dujic, D.: 'Marine DC Power Distribution Networks', PCIM Europe 2019, Nuremberg, Germany, May 2019, pp. 1-8

[5] Ulissi, G., Lee, S.-Y., and Dujic, D.: 'Solid-State Bus-Tie Switch for Shipboard Power Distribution Networks', in
IEEE Transactions on Transportation Electrification, vol. 6, no. 3, pp. 1253-1264, 2020

[6] Ulissi, G., Lee, S.-Y., and Dujic, D.: 'Scalable Solid-State Bus-Tie Switch for Flexible Shipboard Power Systems', in IEEE Transactions on Industrial Electronics, vol. 36, no. 1, pp. 239-247, 2021

[7] Kim, S., Kim, S.-N., and Dujic, D.: 'Extending Protection Selectivity in DC Shipboard Power Systems by Means of Additional Bus Capacitance', in IEEE Transactions on Industrial Electronics, vol. 3, no. 1, pp. 3673-3683, 2020

[8] Skjong, E., Johansen, A., Molinas, M., and Sorensen, A.: 'Approaches to Economic Energy Management in Diesel-Electric Marine Vessels', in IEEE Transactions on Transportation Electrification, vol. 3, no. 1, pp. 22-35, 2017

[9] Settemsdal, S., Haugan, E., Aagesen, K., and Zahedi, B.: 'New Enhanced Safety Power Plant Solution for DP Vessels Operated in Closed Ring Configuration', Dynamic Positioning Conference, Houston, USA, October 2014, pp. 1-21

[10] Hansen, J. Lindtjorn, J., and Vanska, K.: 'Onboard DC Grid for Enhanced DP Operation in Ships', Dynamic Positioning Conference, Houston, USA, October 2011, pp. 1-8

[11] IEC/ISO/IEEE 80005-1: Utility connections in port - Part 1: High Voltage Shore Connection (HVSC) Systems General requirements, 2012 